\title{
Sosialisasi Penanganan Air Limbah Rumah Tangga di Karawang
}

\author{
Ali Khumaidi ${ }^{*}$, Tuntun Rahayu ${ }^{1}$ dan Lydia Darmiyanti ${ }^{1}$ \\ ${ }^{1}$ Universitas Krisnadwipayana, Jl. Kampus Unkris, Jatiwaringin, Pondok Gede, Jakarta Timur \\ *Email korespondensi: alikhumaidi@unkris.ac.id
}

\begin{abstract}
Abstrak
Dampak pencemaran air limbah rumah tangga dapat menyebabkan gangguan pada organisme air yang disebabkan oleh kurangnya kandungan oksigen, adanya ledakan jumlah populasi ganggang dan tumbuhan air, pendangkalan dasar perairan, punahnya biota air, banjir serta menjalarnya wabah penyakit. Adapun penyakit yang ditularkan melaui air dikelompokkan 4 kategori yaitu water borne diseases, water washed diseases, water based diseases, dan water related insect vector diseases. Kondisi sosial dan pengetahuan yang cukup rendah dari masyarakat Dusun Rumambe II Desa Anggadita Karawang dapat memicu dampak pencemaran air. Salah satu usaha untuk mengatasi permasalahan tersebut adalah dengan melaksanakan sosialisasi penanganan air limbah rumah tangga dengan memberikan pengetahuan kesehatan lingkungan, air bersih, sanitasi lingkungan, dan sistem pengolahan air limbah rumah tangga. Bentuk sosialisasi tersebut berupa penyuluhan dan diskusi. Sosialiasasi tentang air limbah, air bersih, masalah dan indikator kesehatan lingkungan, contoh sanitasi lingkungan yang baik dan buruk, penyakit yang bisa disebarkan melalui air, sistem pengolahan air limbah rumah tangga, dan pencemaran lingkungan kepada masyarakat dusun Rumambe II diharapkan mampu mengubah kebiasaan yang salah sehingga mampu mewujudkan lingkungan sehat dan nyaman.
\end{abstract}

Kata kunci: Sosialisasi, Penanganan, Air Limbah Rumah Tangga, Dusun Rumambe II

\begin{abstract}
The impact of pollution of household wastewater can cause disruption of the life of aquatic organisms due to reduced oxygen content, the explosion of populations of algae and aquatic plants, siltation of bottom of the waters, extinction of aquatic biota, floods and spread of epidemics. The diseases transmitted through water are grouped into 4 categories, namely water borne diseases, water washed diseases, water based diseases, and water related insect vector diseases. The social conditions and knowledge that are quite low from the Dusun Rumambe II, AnggaditaVillage, Karawang can trigger the effects of water pollution. One effort to overcome these problems is to carry out socialization of household waste water treatment by providing knowledge of environmental health, clean water, environmental sanitation, and household wastewater treatment systems. The form of socialization is in the form of counseling and discussion. Socialization of waste water, clean water, environmental health problems and indicators, examples of good and bad environmental sanitation, diseases that can be transmitted through water, household wastewater treatment systems, and environmental pollution to the people of Dusun Rumambe II are expected to be able to change wrong habits so as to create a healthy and comfortable environment.
\end{abstract}

Keywords: Socialization, Handling, Household Wastewater, Dusun Rumambe II

Format Sitasi: Khumaidi, A., Rahayu, T \& Damayanti, L. (2019). Sosialisasi Penanganan Air Limbah
Rumah Tangga di Karawang.
http://dx.doi.org/10.29405/solma.v8i2.3165

Diterima: 25 Februari 2019 | Revisi: 24 September 2019 | Dipublikasikan: 21 Oktober 2019 
(C) 2019. Oleh authors. Lisensi Jurnal Solma, LPPM-Uhamka, Jakarta. Artikel ini bersifat open access yang didistribusikan di bawah syarat dan ketentuan Creative Commons Attribution (CC-BY) license. (http://creativecommons.org/licenses/by/4.0/).

\section{PENDAHULUAN}

Air merupakan suatu zat ciptaan Tuhan YME yang menjadi salah satukomponen terpenting dalam kehidupan. Sebagai komponen penting dalam kehidupan, air wajib kita jaga dan lestarikan. Cara-cara dalam konservasi air harus diketahui dan dilaksanakan dalam keseharian supaya kelestaarian air dapat berlangsung hingga masa depan. Sungai Citarum merupakan sumber air terbesar di Jawa Barat yang memiliki potensi bagi masyarakat, dapat berupa potensi yang menguntungkan ataupun potensi yang merugikan (Chayatin, 2009).

Kerusakan lingkungan yang terjadi pada DAS Citarum terjadi dari hulu hingga ke hilir. Hal ini berdampak pada ketersediaan sumberdaya air, baik air tanah dan air permukaan serta adanya penurunan muka air tanah. Kodam Siliwangi pada tahun 2017 melalui tim surveinya mencatat sebanyak 20.462 ton sampah domestik yang terbagi atas sampah organik dan anorganik yang dibuang ke dalam sungai Citarum. Ditambah lagi adanya limbah harian 35,5ton dari tinja manusia dan 56 ton dari kotoran ternak. Hasil uji klinis BBPOM Bandung menyatakan bahwa air sungai Citarum berpotensi sangat beracun karena mengandung berbagai zat berbahaya bagi tubuh manusia seperti sulfur, merkuri, coliform, mangan,ferum, klor dan timbal. Berbagai bakteri seperti ecoli, pseudomonas aeroginosa, dapat memicu penyebaran wabah kpenyakit ke masyarakat, ditambah adanya limbah medis yang dibuang ke sungai (Zakia, Dwi Agustina, 2019)

Pemerintah telah membuat peraturan dan kebijakan untuk menanggulangi masalah pada sungai Citarum melalui Peraturan Presiden Nomor 15 Tahun 2018 tentang Percepatan Pengendalian Pencemaran dan Kerusakan DAS Citarum (Perpres, 2015). Peran serta pemerintah dengan melakukan reviltalisasi lahan dan tindakan lainnya yang berkaitan dengan anak sungai, limbah pabrik, limbah rumah tangga diharapkan air sungai Citarum dan sekitarnya dapat bermanfaat untuk pertanian, air baku, air tanah sehingga mendukung kehidupan yang lebih baik (Suarna, 2008).

\section{MASALAH}

1. Kondisi sosial dan perekomomian yang kurang baik pada masyarakat Dusun Rumambe II memicu lingkungan tempat tinggal yang kurang sehat dan nyaman. 
Kurangnya pengetahuan tentang lingkungan yang sehat serta sanitasinya, bahaya limbah air rumah tangga, kebiasaan yang acuh terhadap lingkungan dapat menyebabkan wabah penyakit serta banjir pada musim hujan. Pembangunan jamban keluarga dan sistem pengolahan air limbah yang tidak sesuai akan mempengaruhi kondisi air bersih dan air minum bagi masyarakat.

\section{METODE PELAKSANAAN}

Metode pelaksanaan pada kegiatan pengabdian masyarakat ini yaitu perencanaan, pelaksanaan, dan evaluasi. Adapun penjelasannya sebagai berikut.

1. Tahap perencanaan

Kegiatan pengabdian masyarakat ini diawali dengan mengajukan proposal kepada Unit P2M Fakultas Teknik Universitas Krisnadwipayana. Tahap selanjutnya yaitu mengurus perizinan kegiatan kepada pihak pihak masyarakat dan pemerintahan Desa Anggadita Karawang. Kami juga melakukan kunjungan awal untuk melihat kondisi dan diskusi dengan tata pamong terkait permasalahan di wilayahnya. Kemudian kami mempersiapkan materi sosialisasi yang akan diberikan kepada masyarakat (Dinkes, 2016).

2. Tahap Pelaksanaan

Kegiatan berlangsung di Dusun Rumambe II, Desa Anggadita, Karawang. Kegiatan dilaksanakan selama 2 hari. Hari pertama berisi kegiatan sosialisasi dan diskusi. Hari kedua berisi kegiatan diskusi lanjutan dan tanyajawab untuk evaluasi tingkat pengetahuan dan penerimaan materi.

Tabel 1. Materi dan Metode Sosialisasi

\begin{tabular}{clc}
\hline No & \multicolumn{1}{c}{ Materi } & \multicolumn{1}{c}{ Metode } \\
\hline 1 & Air limbah & Penyuluhan dan Diskusi \\
2 & Air bersih & Penyuluhan dan Diskusi \\
3 & Masalah dan indikator kesehatan lingkungan & Penyuluhan dan Diskusi \\
4 & Contoh sanitasi yang baik dan buruk & Penyuluhan dan Diskusi \\
5 & Penyakit yang bisa ditularkan lewat media air & Penyuluhan dan Diskusi \\
6 & Sistem pengolahan air limbah rumah tangga & Penyuluhan dan Diskusi \\
\hline
\end{tabular}

3. Tahap Evaluasi

Pada tahap dilakukan evaluasi kegiatan terhadap tahap perencanaan dan tahap pelaksanaan. Evaluasi perencanaan bertujuan untuk mengukur tingkat persiapan kegiatan pengabdian masyarakat dengan melakukan pertemuan kepada seluruh tim yang terlibat di dalam pengabdian masyarakat. Evaluasi tahap pelaksanaan bertujuan untuk mengukur pencapaian target acara dengan indikator penilaian yang terdiri dari: 
ketepatan waktu, keteraturan acara, jumlah peserta, kepuasan peserta terhadap penyampaian materi sosialisasi, antusiasme peserta serta aktivitas diskusi. Setelah evaluasi selesai dilaksanakan, dilanjutkan dengan menyusun laporan pertanggungjawaban kegiatan pengabdian masyarakat (Crompton, Burke, Gregory, \& Gräbe, 2016).

\section{HASIL DAN PEMBAHASAN}

Pada pembahasan ini akan dijabarkan materi dalam sosialiasi Penanganan Air Limbah Rumah Tangga.

1. Air Limbah

Secara definisi air limbah ialah kondisi dimana kualitas air mengalami penurunan. Sedangkan limbah rumah tangga ialah limbah dari hasil pembuangan dari dapur, cucian, kamar mandi dan kotoran manusia. Limbah rumah tangga berdasarkan wujudnya dibagi menjadi 3 yaitu limbah padat atau sampah, limbah cair (greywater dan blackwater) dan limbah gas. Sedangkan limbah berdasar asalnya dibedakan limbah organik dan anorganik (Suhandang, 2004).

2. Air Bersih

Air bersih ialah air yang dipakai dalam kebutuhan sehari-hari baik untuk memasak, mandi, mencuci, dan lainnya yang secara kualitas dapat mendukung dalam kesehatan dan bisa digunakan untuk minum jika telah diolah. Air minum juga dapat diartikan air yang telah melewati proses pengolahan ataupun belum yang mampu memenuhi syarat kesehatan dan dapat langsung diminum (Wardhana, 2001).

3. Masalah dan dan indikator kesehatan lingkungan

Masalah kesehatan lingkungan dapat disebabkan beberapa hal sebagai berikut:
a. Air bersih
e. Serangga dan binatang pengganggu
b. Pembuangan kotoran/tinja
f. Makanan dan minuman
c. Kesehatan pemukiman
g. Pencemaran lingkungan
d. Pembuangan sampah

Sedangkan indikator kesehatan lingkungan ditentukan oleh: 

a. Rumah sehat
b. Akses air minum
c. Jarak ke sumber air minum dengan tempat penampungan air kotoran
d. Fasilitas tempat buang air besar
e. Luas Lantai Pengendalian lingkungan

4. Sanitasi Lingkungan

Sanitasi lingkungan dapat ditentukan oleh permasalahan berikut:
a. Pembuangan air limbah langsung ke sungai
b. Warga BAB sembarangan
c. Kualitas jamban
d. Belum adanya pembuangan tinja (septic tank)
e. Drainase yang kurang baik
f. Buang sampah ke sungai
g. Belum adanya TPS/TPA

5. Penyakit yang dapat ditularkan melalui air

Penyakit yang bisa disebarkan atau ditukarkan lewat air dikelompokkan dalam 4 kategori yaitu:

Water borne diseases, ialah penyakit yang dalam penyebarannya atau penularannya langsung melewati air minum yang memiliki kandungan patogen. Sebagai contoh: penyakit disentri, hepatitis, demam tifoid, kolera, gastroenteritis (Yang \& Mei, 2018).

Water washed diseases, ialah penyakit yang dalam penyebarannya dikarenakannya kurangnya air dalam kebersihan seseorang. Seperti penyakit infeksi jamur, scabies. Adapun penyakit tersebut biasanya diakibatkan kurang bersih dalam cuci tangan, gosok gigi, mandi, dan lainnya (Listyani, 2004).

Water based diseases, ialah penyakit yang disebarkan bibit penyakit yang siklus hidup dalam air. Seperti penyakit schistosomiasis.

Water related insect vector diseases, adalah penyakit yang ditularkan melalui vektor yang hidupnya tergantung pada air. Contoh: malaria, demam.

6. Sistem pengolahan air limbah rumah tangga

Dalam pengolahan dibedakan menjadi 2, yaitu:

a. Sanitasi sistem setempat (on site system) 
Pengolahan air limbah berada didalam sebidang tanah milik individu. Contohnya: cubluk atau septik tank.

b. Sanitasi sistem terpusat (off site system)

Pengolahan air limbah berada diluar atau pembuangannya disalurkan ke sebidang tanah yang berada diluar melalui pipa dengan jarak tertentu. Tempat ini digunakan secara bersama dan dialirkan ke instalasi pengolahan air limbah (Hendalia E. Fahmida M, Revis A, 2017).

Jamban sehat yaitu sarana yang digunakan untuk melakukan buang air besar yang memenuhi persyaratan kesehatan. Jamban sehat tidak meyebabkan tersebarnya bahan berbahaya dan mampu mengantisipasi pembawa penyakit bagi manusia dan lingkungan. Air bersih dapat dipengaruhi oleh jamban keluarga. Jamban yang tidak sehat bisa mengakibatkan pencemaran pada sumber air. Oleh karena itu sebaiknya kita mengupayakan supaya jamban memenuhi persyaratan kesehatan. Karena jika sumber air telah teercemar maka akan diperlukan biaya dalam pengolahan dan pengelolaannya (Zakia, Dwi Agustina, 2019).

Pemukiman yang baik harus memenuhi syarat kesehatan lingkungan sebagai berikut:

1. Adanya sistem drainase yang baik

2. Adanya tanaman atau pohon

3. Adanya sumur resapan atau sanitasi

4. Tersedianya pembuangan sampah

5. Ventilasi yang baik dalam bangunan rumah

Dengan demikian dapat menghindari dampak pencemaran air yang meliputi:

1. Adanya gangguan pada biota air yang disebabkan kurang oksigen

2. Adanya ledakan populasi tumbuhan air tumbuhan air, seperti: ganggang

3. Proses dasar perairan yang dangkal

4. Adanya kepunahan pada biota air

Banjir yang disebabkan saluran air yang tidak baik atau tersumbat Penyebaran wabah penyakit

\section{KESIMPULAN}

Hasil limbah dari rumah tangga baik yang berwujud padat, cair dan gas makin meningkat dan pembuangannya sebagian besar tidak pada tempatnya, bahkan mengalir ke 
sungai. Hal ini menyebabkan pencemaran pada lingkungan, mulai dari pencemaran air hingga pencemaran udara. Oleh karena itu perlu pengelolaan air limbah rumah tangga yang baik antara lain yaitu dengan membuat tempat penampungan air limbah, septic tank baik sendiri maupun bersama (komunal). Melalui kegiatan pengabdian masyarakat ini, kami pelaksana pengabdian melakukan kegiatan sosialisasi tentang air limbah, air bersih, masalah dan indikator kesehatan lingkungan, contoh sanitasi lingkungan baik dan buruk, penyakit yang bisa disebarkan lewat air, sistem pengolahan air limbah rumah tangga, dan pencemaran lingkungan berhasil memberikan pengetahuan pada masyarakat. Hal ini terlihat dari antusiasme masyarakat dan tata pamong dusun serta meningkatnya pengetahuan dari hasil diskusi yang dilaksanakan.

\section{UCAPAN TERIMA KASIH}

Penulis ucapkan terimakasih kepada P2M FT UNKRIS yang telah telah memberikan dana untuk kegiatan pengabdian masyarakat yang penulis lakukan. Tidak lupa pula kami ucapkan kepada Pihak Dusun Rumambe II, Desa Anggadita yang telah memberikan kesempatan waktu dan tempat untuk sosialisasi. Serta semua pihak yang membantu proses pengabdian dari perencanaan sampai evaluasi.

\section{DAFTAR PUSTAKA}

Chayatin, N. (2009). Ilmu Kesehatan Masyarakat Teori dan Aplikasi. Jakarta: Salemba Medika.

Crompton, H., Burke, D., Gregory, K. H., \& Gräbe, C. (2016). The Use of Mobile Learning in Science: A Systematic Review. Journal of Science Education and Technology, 25(2), 149-160. https://doi.org/10.1007/s10956-015-9597-X

Dinkes, dinkes. (2016). Dinas Kesehatan Provinsi DKI. 2016. Profil Kesehatan Provinsi DKI Jakarta Tahun 2016. Bidang Perencanaan dan Pembiayaan Dinas Kesehatan Provinsi DKI Jakarta.

Hendalia E. Fahmida M, Revis A, H. (2017). Aplikasi Probio_FMPlus melalui Air Minum pada Ayam Broiler di Politani Kupang Jurnal Ilmu-Ilmu Peternakan, 20, 33-38.

Listyani, W. (2004). Tanaman Alternatif untuk Hipertensi. Retrieved from http://www.kompas.com/kompas-cetak/.

Perpres. Peraturan Presidan RI No. 2 Tahun 2015 tentang Rencana Pembangunan Jangka Menengah Nasional 2015-2019. (2015).

Suarna, I. W. (2008). Model Penanggulangan Sampah Perkotaan dan Pedesaan (Universita). bali. 
Suhandang, K. (2004). Pengantar Jurnalistik, Seputar Organisasi, Produk \& Kode Etik. Bandung: Nuansa.

Wardhana, W. (2001). Dampak pencemaran lingkungan. yogyakarta: Andi Offset.

Yang, S., \& Mei, B. (2018). Understanding learners' use of augmented reality in language learning: insights from a case study. Journal of Education for Teaching, 1-3. https://doi.org/10.1080/02607476.2018.1450937

Zakia, Dwi Agustina, M. P. D. (2019). Mewujudkan Sistem Pengelolaan Sampah Melalui Program Citarum Harum. Jurnal Komunitas: Jurnal Pengabdiankepada Masyarakat, 2(1), 38-43. 